\title{
OPINION
}

Open Access

\section{Diet, a new target to prevent depression?}

\author{
Almudena Sanchez-Villegas ${ }^{1 *}$ and Miguel A Martínez-González²
}

\begin{abstract}
Background: Research on the role of diet in the prevention of depression is scarce. Some evidence suggests that depression shares common mechanisms with cardiovascular disease.

Discussion: Before considering the role of diet in the prevention of depression, several points need to be considered. First, in general, evidence has been found for the effects of isolated nutrients or foods, and not for dietary patterns. Second, most previous studies have a cross-sectional design. Third, information is generally collected though questionnaires, increasing the risk of misclassification bias. Fourth, adequate control of confounding factors in observational studies is mandatory.

Summary: Only a few cohort studies have analyzed the relationship between overall dietary patterns, such as the Mediterranean diet, and primary prevention of depression. They have found similar results to those obtained for the role of this dietary pattern in cardiovascular disease. To confirm the findings obtained in these initial cohort studies, we need further observational longitudinal studies with improved methodology, as well as large randomized primary prevention trials, with interventions based on changes in the overall food pattern, that include participants at high risk of mental disorders.
\end{abstract}

Keywords: Cohort study, dietary patterns, Mediterranean diet, omega-3, trans fatty acids, nutrigenetics, primary prevention trial

\section{Background}

The prevention of mental disorders is a priority due to their huge health, social and economic burden. Among them, unipolar major depression is the worldwide leading cause of years of healthy life lost as a result of disability [1] and it is projected to also be the leading cause of disability-adjusted life years lost in 2030 [2]. Surprisingly, relatively little etiological longitudinal research has been conducted to assess which are the dietary or lifestyle determinants of depression. In this context, dietary factors are likely to play a major role. Whereas the role of diet in the prevention of other noncommunicable diseases, such as cardiovascular disease (CVD), has been widely investigated for the last 50 years, the relationship between diet and depression is so far a novel and interesting field that has only emerged in the last five to ten years.

\footnotetext{
* Correspondence: asanchez@dcc.ulpgc.es

'Deparment of Clinical Sciences, University of Las Palmas de Gran Canaria,

PO Box 550, CP 35080, Las Palmas de Gran Canaria, Spain

Full list of author information is available at the end of the article
}

Depression, cardiovascular disease, metabolic syndrome and obesity

There is an accrual of studies suggesting that depression seems to share common mechanisms with the metabolic syndrome (MetS), obesity and CVD. In fact, several major cardiovascular risk factors (including obesity and MetS) are more prevalent among patients who are depressed [3]. Metabolic and inflammatory processes, such as reduced insulin sensitivity, elevations in plasma homocysteine levels and, more importantly, increased production of proinflammatory cytokines and endothelial dysfunction, may be responsible for the link between depression and cardiometabolic disorders [4-6].

Proinflammatory cytokines production interferes with neurotransmitters metabolism and decreases the availability of some precursors such as tryptophan [7]. Moreover, low-grade inflammatory status and endothelial dysfunction inhibit the expression of brain-derived neurotrophic factor (BDNF) because it is the endothelial cells that synthesize and secrete BDNF. An emerging concept in neuroscience is that perturbations in the health of the cerebral endothelium (including some loss of the neuroprotection afforded by BDNF) may mediate progressive neuronal dysfunction 
[8]. Indeed, results of several meta-analyses have established that BDNF levels are reduced in patients with depression, and that antidepressant medication seems to up-regulate their levels $[9,10]$.

\section{Discussion}

The role of diet in depression: nutrients or foods versus dietary patterns

To date, most of the evidence relating diet to depression is similar to that demonstrating the role that diet plays on MetS or CVD. This is reasonable, because both diseases seem to share several common physiopathological mechanisms. This analogy is supported by the beneficial effects reported for lipids with anti-inflammatory properties, such as omega-3 fatty acids or olive oil [11,12]. Conversely, the intake of trans fatty acids or the consumption of foods rich in this kind of fat, like fast food or commercial bakery products, have recently been reported as contributors to higher depression risk [12-14]. The mediators of adverse effects of trans fatty acids on CVD include increases in plasma concentrations of low density lipoprotein -cholesterol, reductions in high density lipoprotein -cholesterol, proinflammatory changes, and endothelial dysfunction. Because depression is also associated with a low-grade inflammatory status, endothelial dysfunction and worse lipid profiles, the adverse biological modifications caused by trans fatty acids could also be responsible for detrimental effects on depression.

However, it is more important to study the overall dietary pattern than isolated nutrients. In this context, it is reasonable to think that dietary patterns that foster cardiometabolic health could also be inversely related to depressive disorders. Similarly, those dietary patterns directly involved in cardiometabolic risk could also exert a detrimental effect on depression. A few epidemiological studies have inversely related healthy dietary patterns, including the Mediterranean Diet, or directly related the Western dietary pattern to the risk of developing depression [15-19]. Significant differences in plasma BDNF levels have been observed for patients with depression who were assigned to the Mediterranean diet compared with those assigned to a control diet [20]. Nevertheless, these evidences are sparse and not definitive, because some of these studies were not well-protected against diverse sources of bias.

\section{Epidemiological evidences: strengths and limitations}

Some of the reported associations between diet and depression have been found in studies with large sample sizes. These large studies generally use questionnaires to collect information on the outcome (depression) and/or the exposure (diet). Food frequency questionnaires have been customarily used, but they are known to have some potential for misclassification bias. The use of questionnaires adequately validated in the country where the study was performed is encouraged to minimize misclassification biases. Depression assessment is usually based on depressive symptoms scales. Very often this information is self-reported. Additionally, the choice of a cut-off point to define depression is generally arbitrary. This cut-off point usually depends on the sample characteristics and limits the ability to conduct comparisons between studies carried out in different populations. Thus, the use of medical diagnoses of depression ascertained via clinical assessments or the use of a validated self-reported medical diagnosis of depression could be the most appropriate approach to reduce misclassification problems in large epidemiological studies.

Most of the evidence suggesting a link between nutrition and depression comes from studies with a cross-sectional design. This design usually precludes the possibility to infer a truly causal relationship. In these studies exposure is ascertained simultaneously with disease and, therefore, results could be alternatively interpreted as a consequence of reverse causation bias, that is, depression may lead to poorer dietary habits. Beyond cross-sectional studies, only a few longitudinal studies have prospectively analyzed the role of diet on depression risk. One of these epidemiological studies is the Seguimiento Universidad de Navarra (SUN) Project, a dynamic prospective cohort of university graduates, with a median follow-up of 6 years and the ability to include more than 10,000 participants in longitudinal assessments. Several diet components have been prospectively associated with depression risk in this cohort. Whereas trans fatty acids or fast food and commercial bakery products were associated with higher depression risk $[12,13]$, omega-3 fatty acids and olive oil intake showed inverse associations $[11,12]$. Moreover, the SUN Project reported in 2009 that better adherence to the traditional Mediterranean dietary pattern was associated with substantially reduced depression risk [15]. Almost immediately after, investigators from the Whitehall II longitudinal study (another prospective cohort in the UK) reported a detrimental role for a Western dietary pattern [16]. Recently, the divergent roles of healthy or Western dietary patterns on depression risk have been confirmed in a longitudinal analysis of Australian adolescents [17]. Other studies conducted on adults in Australia (Geelong Osteoporosis Study) and Norway (Hordaland Health Study) reported similar associations between dietary patterns and depression risk $[18,19]$, but they were based on cross-sectional assessments. Thus, these initial findings need to be confirmed (ideally in these same cohorts) in future prospective assessments.

Finally, the potential effect of dietary patterns on depression could be in part explained by the co-occurrence of other lifestyle-related factors such as physical activity, 
alcohol intake, smoking or the use of illicit drugs; by sociodemographic factors such as social networks, marital status or socioeconomic level; or by medical conditions such as the presence of CVD. Thus, one of the most important aspects in observational epidemiology is to obtain an adequate control of these possible confounders. Most of these confounders are usually collected in welldesigned epidemiological studies and controlled using multivariable models. Restriction is an even better procedure (at least as a sensitivity analysis) that is used on occasion. This procedure consists of excluding all participants with the presence of the confounding condition (that is, cases of prevalent CVD) from the database before assessing the role of diet on incident depression. Nevertheless, when the lack of or inadequate control for some of these potential confounders and the presence of residual confounding exist, the interpretation of the findings obtained from observational studies demands caution.

\section{Prevention or treatment}

Whereas the above-mentioned studies have analyzed the role of diet in the primary prevention of depression, clinical trials have been generally designed to assess the impact of nutritional interventions on the clinical course of depression. However, most available trials are based on small samples and have been carried out in a controlled clinical setting with a short follow-up period. Moreover, with the exception of a recent clinical trial [21], none of these trials has analyzed the effect of an overall dietary pattern. Instead they have assessed isolated nutrients, mainly omega-3 fatty acids or B vitamins [22,23].

\section{Interaction between diet and genetic factors}

To date, there are no studies that ascertain the possible interaction between diet and genetic factors on depression risk. Nevertheless, effect modification of genetic factors by diet on several diseases potentially related to depression, such as obesity or CVD, has been increasingly reported $[24,25]$. This new line of nutrigenetics research based on the hypothesis that visceral obesity or MetS share some etiological mechanisms, including diet and genes, with unipolar depressive disorder should be developed in the near future. This would help to better understand the role of diet on the risk and prognosis of major depression.

\section{Future research directions}

Large randomized primary prevention trials with interventions based on changes in the overall food pattern and including participants at high risk of mental disorders could provide the most definitive answer to confirm or refute experimentally the findings reported by observational studies. Though ideal, these trials might not seem feasible. However, similar trials have been successfully conducted in cardiovascular fields, as it has been the case for the Dietary Approaches to Stop Hypertension (DASH) diet [26] or the Prevención con Dieta Mediterránea (PREDIMED) trial [27]. Why cannot similar trials be designed for the primary prevention of depression?

\section{Summary}

Although a few prospective cohort studies have analyzed the role of dietary patterns on depression risk, their contributions are still scarce. Further observational studies with improved methodology (including repeated measurements of diet, better validation of measuring instruments, longer follow-up periods, larger sample sizes and adequate control of confounders) as well as large randomized primary prevention trials with interventions based on changes in the overall food pattern and including participants at high risk of mental disorders are necessary to confirm the findings obtained in these initial studies.

\section{Abbreviations}

BDNF: brain derived neurotrophic factor; CVD: cardiovascular disease; DASH: Dietary Approaches to Stop Hypertension; MetS: metabolic syndrome; PREDIMED: Prevención con Dieta Mediterránea; SUN: Seguimiento Universidad de Navarra.

\section{Authors' contributions}

ASV wrote the manuscript drafts. MAMG read and critically revised manuscript drafts. Both authors read and approved the final manuscript.

\section{Authors' information}

ASV is an Associate Professor of Preventive Medicine and Public Health at the University of Las Palmas of Gran Canaria. She has been funded with several grants from the Instituto De Salud Carlos III, Official Agency of the Spanish Government for biomedical research to analyze the role of diet in depression in the SUN Project. MAMG is a Professor of Preventive Medicine and Public Health at the University of Navarra and the director of the SUN Project.

\section{Competing interests}

The authors declare that they have no competing interests.

\section{Acknowledgements}

We thank all the participants and other members of the SUN Project: Alonso A, Balaguer A, Benito S, Bes-Rastrollo M, Beunza JJ, Carlos S, De la FuenteArrillaga C, De Irala J, Delgado-Rodriguez M, Guillén-Grima F, Krafka J, Llorca J, López del Burgo C, Marti A, Martinez JA, Nuñez-Cordoba JM, Pimenta AM, Ruiz-Canela M, Sanchez D, Segui-Gomez M, Serrano-Martinez M, Toledo E, Vazquez Z.

The SUN Study has received funding from the Spanish Government (Grants PI01/0619, PI030678, PI040233, PI042241, PI050976, PI070240, PI070312, PI081943, PI080819, PI1002658, PI1002293, RD06/0045, G03/140 and 87/ 2010), the Navarra Regional Government (36/2001, 43/2002, 41/2005, 36/ 2008) and the University of Navarra.

\section{Author details}

${ }^{1}$ Deparment of Clinical Sciences, University of Las Palmas de Gran Canaria, PO Box 550, CP 35080, Las Palmas de Gran Canaria, Spain. ²Department of Preventive Medicine and Public Health, University of Navarra, C/Irunlarrea 1 CP 31008, Pamplona, Spain.

Received: 20 June 2012 Accepted: 3 January 2013

Published: 3 January 2013 


\section{References}

1. Mathers CD, Lopez AD, Murray CJL: The burden of disease and mortality by condition: data, methods, and results for 2001. In Global Burden of Disease and Risk Factors. Edited by: Lopez AD, Mathers CD, Ezzati M, Jamison DT, Murray CJL. Washington D.C.: World Bank Publications; 2006:45-240

2. World Health Organization: The Global Burden of Disease 2004 Update Geneva, Switzerland: World Health Organization; 2008.

3. Luppino FS, de Wit LM, Bouvy PF, Stijnen T, Cuijpers P, Penninx BW, Zitman FG: Overweight, obesity, and depression: a systematic review and meta-analysis of longitudinal studies. Arch Gen Psychiatry 2010, 67:220-229.

4. Gimeno D, Kivimaki M, Brunner EJ, Elovainio M, De Vogli R, Steptoe A, Kumari M, Lowe GD, Rumley A, Marmot MG, Ferrie JE: Associations of Creactive protein and interleukin- 6 with cognitive symptoms of depression: 12-year follow-up of the Whitehall II study. Psychol Med 2009, 39:413-423.

5. Do DP, Dowd JB, Ranjit N, House JS, Kaplan GA: Hopelessness, depression, and early markers of endothelial dysfunction in U.S. adults. Psychosom Med 2010, 72:613-619.

6. Almeida OP, McCaul K, Hankey GJ, Norman P, Jamrozik K, Flicker L: Homocysteine and depression in later life. Arch Gen Psychiatry 2008, 65:1286-1294.

7. Miura H, Ozaki N, Sawada M, Isobe K, Ohta T, Nagatsu T: A link between stress and depression: shifts in the balance between the kynurenine and serotonin pathways of tryptophan metabolism and the etiology and pathophysiology of depression. Stress 2008, 11:198-209.

8. Guo S, Kim WJ, Lok J, Lee SR, Besancon E, Luo BH, Stins MF, Wang X, Dedhar S, Lo EH: Neuroprotection via matrix-trophic coupling between cerebral endothelial cells and neurons. Proc Natl Acad Sci USA 2008, 105:7582-7587.

9. Bocchio-Chiavetto L, Bagnardi V, Zanardini R, Molteni R, Nielsen MG, Placentino A, Giovannini C, Rillosi L, Ventriglia M, Riva MA, Gennarelli M: Serum and plasma BDNF levels in major depression: a replication study and meta-analyses. World J Biol Psychiatry 2010, 11:763-773.

10. Sen S, Duman R, Sanacora G: Serum brain-derived neurotrophic factor, depression, and antidepressant medications: meta-analyses and implications. Biol Psychiatry 2008, 64:527-532.

11. Sanchez-Villegas A, Henríquez P, Figueiras A, Ortuño F, Lahortiga F, Martínez-González MA: Long chain omega-3 fatty acids intake, fish consumption and mental disorders in the SUN cohort study. Eur J Nutr 2007, 46:337-346.

12. Sánchez-Villegas A, Verberne L, De Irala J, Ruíz-Canela M, Toledo E, SerraMajem L, Martínez-González MA: Dietary fat intake and the risk of depression: the SUN Project. PLoS One 2011, 6:e16268.

13. Sánchez-Villegas A, Toledo E, de Irala J, Ruiz-Canela M, Pla-Vidal J, MartínezGonzález MA: Fast-food and commercial baked goods consumption and the risk of depression. Public Health Nutr 2012, 15:424-432.

14. Liu C, Xie B, Chou CP, Koprowski C, Zhou D, Palmer P, Sun P, Guo Q, Duan L, Sun $X$, Anderson Johnson C: Perceived stress, depression and food consumption frequency in the college students of China Seven Cities. Physiol Behav 2007, 92:748-754.

15. Sánchez-Villegas A, Delgado-Rodríguez M, Alonso A, Schlatter J, Lahortiga F, Serra Majem L, Martínez-González MA: Association of the Mediterranean dietary pattern with the incidence of depression: the Seguimiento Universidad de Navarra/University of Navarra follow-up (SUN) cohort. Arch Gen Psychiatry 2009, 66:1090-1098.

16. Akbaraly TN, Brunner EJ, Ferrie JE, Marmot MG, Kivimaki M, SinghManoux A: Dietary pattern and depressive symptoms in middle age. $\mathrm{Br} J$ Psychiatry 2009, 195:408-413.

17. Jacka FN, Kremer PJ, Berk M, de Silva-Sanigorski AM, Moodie M, Leslie ER, Pasco JA, Swinburn BA: A prospective study of diet quality and mental health in adolescents. PLoS One 2011, 6:e24805

18. Jacka FN, Mykletun A, Berk M, Bjelland I, Tell GS: The association between habitual diet quality and the common mental disorders in communitydwelling adults: the Hordaland Health study. Psychosom Med 2011, 73:483-490.

19. Jacka FN, Pasco JA, Mykletun A, Williams $L$, Hodge AM, O'Reilly SL, Nicholson GC, Kotowicz MA, Berk M: Association of Western and traditional diets with depression and anxiety in women. Am J Psychiatry 2010, 167:305-311
20. Sánchez-Villegas A, Galbete C, Martinez-González MA, Martinez JA, Razquin C, Salas-Salvadó J, Estruch R, Buil-Cosiales P, Martí A: The effect of the Mediterranean diet on plasma brain-derived neurotrophic factor (BDNF) levels: the PREDIMED-NAVARRA randomized trial. Nutr Neurosci 2011, 14:195-201.

21. García-Toro M, Ibarra O, Gili M, Serrano MJ, Oliván B, Vicens E, Roca M: Four hygienic-dietary recommendations as add-on treatment in depression: a randomized-controlled trial. J Affect Disord 2012, 140:200-203.

22. Bloch $\mathrm{MH}$, Hannestad J: Omega-3 fatty acids for the treatment of depression: systematic review and meta-analysis. Mol Psychiatry 2012, 17:1272-1282.

23. Taylor MJ, Carney SM, Goodwin GM, Geddes JR: Folate for depressive disorders: systematic review and meta-analysis of randomized controlled trials. J Psychopharmacol 2004, 18:251-256.

24. Razquin C, Martinez JA, Martinez-Gonzalez MA, Fernández-Crehuet J, Santos JM, Marti A: A Mediterranean diet rich in virgin olive oil may reverse the effects of the $-174 \mathrm{G} / \mathrm{C}$ IL6 gene variant on 3-year body weight change. Mol Nutr Food Res 2010, 54(Suppl 1):75-82.

25. Lairon D, Defoort C, Martin JC, Amiot-Carlin MJ, Gastaldi M, Planells R: Nutrigenetics: links between genetic background and response to Mediterranean-type diets. Public Health Nutr 2009, 12:1601-1606.

26. Appel LJ, Moore TJ, Obarzanek E, Vollmer WM, Svetkey LP, Sacks FM, Bray GA, Vogt TM, Cutler JA, Windhauser MM, Lin PH, Karanja N: A clinical trial of the effects of dietary patterns on blood pressure. DASH Collaborative Research Group. N Engl J Med 1997, 336:1117-1124.

27. Martínez-González MÁ, Corella D, Salas-Salvadó J, Ros E, Covas MI, Fiol M, Wärnberg J, Arós F, Ruíz-Gutiérrez V, Lamuela-Raventós RM, Lapetra J, Muñoz MÁ, Martínez JA, Sáez G, Serra-Majem L, Pintó X, Mitjavila MT, Tur JA, del Portillo MP, Estruch R, PREDIMED Study Investigators: Cohort profile: design and methods of the PREDIMED study. Int J Epidemiol 2012, 41:377-385.

Pre-publication history

The pre-publication history for this paper can be accessed here: http://www.biomedcentral.com/1741-7015/11/3/prepub

doi:10.1186/1741-7015-11-3

Cite this article as: Sanchez-Villegas and Martínez-González: Diet, a new target to prevent depression? BMC Medicine 2013 11:3.

\section{Submit your next manuscript to BioMed Central and take full advantage of:}

- Convenient online submission

- Thorough peer review

- No space constraints or color figure charges

- Immediate publication on acceptance

- Inclusion in PubMed, CAS, Scopus and Google Scholar

- Research which is freely available for redistribution 